\title{
Method development and validation for simultaneous quantification of microcystin congeners in water
}

\author{
Xiaocui Qiao ${ }^{1,2}, \operatorname{Simin} \mathrm{Ge}^{3}$, Chengyou Liu ${ }^{1,2}$, Lixin Jiao ${ }^{1,2}$, Xue Li ${ }^{1,2}$, Xingru Zhao ${ }^{1,2}$, Tong Qi ${ }^{1,2}$ and Yan Liu ${ }^{1,2^{*}}$ (D)
}

\begin{abstract}
Background: Microcystins (MCs) are secondary metabolites of cyanobacteria that are hepatotoxic to humans through the ingestion of cyanobacteria-contaminated water and accidental inhalation from lake activities. MCs with diverse congeners in water can be precisely quantified using online solid-phase extraction-ultra performance liquid chromatography coupled with tandem mass spectrometry (online-SPE UPLC-MS/MS). A method was developed and validated to simultaneously quantify eight different MCs (microcystin-RR, -LR, -YR, -WR, -LA, -LF, -LY, and -LW) in water using online-SPE UPLC-MS/MS.

Results: The method achieved the highest efficiency and sensitivity by selecting acetonitrile with $0.1 \%$ formic acid and water with $0.1 \%$ formic acid as the best mobile phase conditions. The linearity, accuracy, and precision were validated using matrix-mixed water with a leucine enkephalin internal standard. The limit of detection (LOD) was calculated using the signal-to-noise ratio of three passes of the daily water-surface inspection for MCs. This method showed both high sensitivity and high resolution for the separation of eight $M C$ congeners with LODs ranging from 0.020 to $0.371 \mathrm{ng} \mathrm{L}^{-1}$ and limits of quantitation ranging from 0.066 to $1.24 \mathrm{ng} \mathrm{L}^{-1}$. The detection time was reduced to $11 \mathrm{~min}$. Except for MC-RR (58.8\% recovery at high concentration) and MC-WR (45.1\% and 40.9\% recoveries at medium and high concentrations, respectively), the recoveries of the other MCs ranged from 70 to 135\%, and the relative standard deviation was less than $10 \%$.

Conclusion: Eight different MCs in 12 water samples collected from Chaohu Lake, China, were analyzed. The sum of all MC congeners was calculated to range from 101 to $585 \mathrm{ng} \mathrm{L}^{-1}$ (less than the World Health Organization's safe drinking water limit of $1 \mu \mathrm{g} \mathrm{L}{ }^{-1}$ for MC-LR).
\end{abstract}

Keywords: Microcystin congeners, Filter membranes, Online solid-phase extraction, Detection method development, Lake eutrophication

\section{Background}

Microcystins (MCs) are cyanotoxins produced by many cyanobacteria species [1]. Chemically, MCs are monocyclic heptapeptides with a general structure of cyclo-(-D$\mathrm{Ala}^{1}-\mathrm{L}-\mathrm{X}^{2}$-DisoMeAsp ${ }^{3}-\mathrm{L}-\mathrm{Z}^{4}-\mathrm{Adda}^{5}$-D-isoGlu ${ }^{6}-\mathrm{Mdha}^{7}$ ),

\footnotetext{
*Correspondence: liuyan@craes.org.cn

${ }^{1}$ Environmental Standards Institute of Ministry of Ecology

and Environment of the People's Republic of China, Chinese Research

Academy of Environmental Sciences, Beijing 100012, China

Full list of author information is available at the end of the article
}

where $\mathrm{D}-\mathrm{MeAsp}^{3}$ is $\mathrm{D}$-erythro- $\beta$-methylaspartic acid, $\mathrm{Mdha}^{7}$ is $N$-methyldehydroalanine, and $\mathrm{Adda}^{5}$ is 3-amino-9-methoxy-2,6,8-trimethyl-10-phenyldeca-4, 6-dienoic acid. $\mathrm{X}^{2}$ and $\mathrm{Z}^{4}$ are variable amino acid positions that result in at least 279 variants of MCs in nature [2]. Microcystins are highly toxic because they are specific inhibitors of serine/threonine protein phosphatases that induce the breakdown of the cellular cytoskeleton and promote tumor growth. The greatest environmental risk associated with MCs is from microcystin-contaminated water, which causes animal poisoning and hepatotoxicity

\section{Springer Open}

(c) The Author(s) 2021. Open Access This article is licensed under a Creative Commons Attribution 4.0 International License, which permits use, sharing, adaptation, distribution and reproduction in any medium or format, as long as you give appropriate credit to the original author(s) and the source, provide a link to the Creative Commons licence, and indicate if changes were made. The images or other third party material in this article are included in the article's Creative Commons licence, unless indicated otherwise in a credit line to the material. If material is not included in the article's Creative Commons licence and your intended use is not permitted by statutory regulation or exceeds the permitted use, you will need to obtain permission directly from the copyright holder. To view a copy of this licence, visit http://creativecommons.org/licenses/by/4.0/. 
in humans. Among all the MC congeners, MC-LR is the most common and most studied variant in water samples; thus, it is currently considered to be the reference compound because of its high, acute toxicity and frequent occurrence. The guideline for MC-LR concentration in drinking water $\left(<1.0 \mu \mathrm{g} \mathrm{L}^{-1}\right)$ was established by the World Health Organization (WHO) [3]. In 2010, the International Agency for Research on Cancer (IARC) characterized MC-LR as a Group 2B carcinogen with strong evidence that it supports tumor promotion.

Water blooms usually result in the presence of different MCs simultaneously. Graham et al. detected different cyanotoxin types in $48 \%$ of cyanobacterial blooms, $95 \%$ of which had multiple MC variants [4]. A greater variety of MC congeners was detected in China, where most of the studies were conducted [4-8]. From August 2011 to July 2012, a survey of drinking water sources in the eastern part of Chaohu Lake showed that the total MC concentration reached $8.86 \mu \mathrm{g} \mathrm{L}{ }^{-1}$ [9]. In previous epidemiological studies, the high incidence of developing primary liver cancer in southern China has been correlated with the intake of MC-contaminated drinking water [10, 11]. Therefore, identifying the concentrations of various MCs is critical.

The overall structure of MCs is relatively hydrophilic (polar), which comes from carboxylic acids at positions 3 and 6 and the frequent occurrence of arginine at positions 2 and/or 4 [12]. However, among the wide range of $M C$ variants, there are more lipophilic compounds than MC-LR, which implies that some congeners can be even more toxic than MC-LR [13] The data available in the scientific literature regarding the occurrence and toxicity of MCs other than MC-LR are limited $[14,15]$. The increasing number of toxic structural congeners complicates the identification of MCs. Many techniques have been utilized to analyze MCs, such as immunological and biological assays, UV absorbance, and mass spectrometry [16-19]; enzyme-linked immunosorbent assay (ELISA) kits used to determine MCs are relatively inexpensive, simple, and rapid, but they are less sensitive and selective for target MCs [17, 20, 21]. A method based on direct injection combined with liquid chromatography tandem mass spectrometry (LC-MS/MS) is recommended by the United States Environmental Protection Agency for the detection of six MC congeners (MC-LA, MC-LF, MC-LR, MC-LY, MC-RR, and MC-YR) in drinking water samples [22]. However, the poor sensitivity of this method is a limitation. In addition, the ability to characterize individual congeners present in a given sample is limited by the availability of analytical standards. Other detection methods have been utilized for analyte separation, with UV absorbance commonly employed, but limitations include low sensitivity (with an LOD of 70-300 $\mu \mathrm{g} \mathrm{L}{ }^{-1}$ ), specificity, and interference from complex matrices [2326]. Ultra-performance liquid chromatography coupled with tandem mass spectrometry (UPLC-MS/MS) has been developed to enhance the sensitivity and specificity of the analytical methods for the detection and quantification of MCs in water samples and complex matrices.

MCs are a potential threat to aquatic animals, plants, and human health, and many types of MCs have been detected at concentrations ranging from several $\mathrm{ng} \mathrm{L}^{-1}$ to several $\mu \mathrm{g} \mathrm{L}^{-1}$. Accurately determining the concentration of MCs is of dire significance for protecting human health and studying the mechanism of bloom outbreaks. The existing methods have limitations depending on the detection type, such as varying detection limits and complex operation; thus, for practicality, a set of scientific and efficient methods for the analysis and detection of MCs in water must be established. The effects of the online-SPE column, membranes, mobile phase, and gradient-elution procedures were fully considered in our study, and water samples from typical areas of Chaohu Lake were also collected to (1) establish a sensitive and accurate analytical method for quantifying eight different MCs (MC-LA, MC-LF, MC-LR, MC-WR, MC-LW, MC-LY, MC-RR, and $M C-Y R)$ in freshwater systems using online-SPE coupled with UPLC-MS/MS; and (2) verify the feasibility of the detection method in typical areas.

\section{Materials and methods}

\section{Chemicals and standards}

Methanol and acetonitrile were purchased from J.T. Baker (USA). All standards of MC-LA, MC-LF, MC-LR, MC-WR, MC-LW, MC-LY, MC-RR, and MC-YR (95\% purity) were obtained from BePure, China. The internal standard leucine enkephalin was purchased from Zhenzhun Biologicals, China. Formic acid was obtained from Waters, USA. Ultrapure water was produced using a Milli-Q water purification system (USA).

MC standard solutions were diluted to $1 \mathrm{mg} \mathrm{L}^{-1}$ with methanol, placed in a brown glass bottle, and stored at $-20{ }^{\circ} \mathrm{C}$. The $1 \mathrm{mg} \mathrm{L}^{-1} \mathrm{MC}$ solution was diluted to the required concentration before each experiment. The leucine enkephalin internal standard solution was diluted to $50 \mu \mathrm{g} \mathrm{L}^{-1}$ with methanol/water $(1: 1, \mathrm{v} / \mathrm{v})$ and stored at $-3{ }^{\circ} \mathrm{C}$.

Mixed calibration standard solutions were serially diluted to $1000,500,200,100,50,20$, and $10 \mathrm{ng} \mathrm{L}^{-1}$ with methanol before use, and then stored at $-20^{\circ} \mathrm{C}$.

\section{Operating conditions of UPLC-MS/MS}

The sample was introduced into the injection loop and transferred to an online-SPE column for analyte preconcentration. The online aqueous mobile phase continued to flow after sample loading to ensure matrix and salt 
removal. The analyte was eluted by back-flushing the online-SPE column using the UPLC mobile phase and separated by the chromatographic column prior to MS/ MS detection.

Eight different MCs were analyzed using an ACQUITY UPLC system coupled to a Xevo TQ-MS (triple-quadrupole MS/MS) mass spectrometer (Waters, Manchester, UK). The analytical column and SPE column were ACQUITY UPLC BEH C18 $(1.6 \mu \mathrm{m}, 2.1 \mathrm{~mm} \times 50 \mathrm{~mm})$ and XBridgeC8 Direct Connect HP $(10 \mu \mathrm{m}$, $2.1 \mathrm{~mm} \times 30 \mathrm{~mm}$ ), respectively. The system was operated in electrospray positive mode (ESI+), with a capillary voltage of $3.70 \mathrm{kV}$, source and desolvation temperatures of $150^{\circ} \mathrm{C}$ and $500{ }^{\circ} \mathrm{C}$, respectively, desolvation gas flow rate of $1000 \mathrm{~L} \mathrm{~h}^{-1}$, cone hole backflush gas pressure of $30 \mathrm{~V}$, cone hole backflush gas flow rate of $50 \mathrm{~L} \mathrm{~h}^{-1}$, and collision gas flow rate of $0.06 \mathrm{~mL} \mathrm{~min}^{-1}$. All parameters were optimized to provide the best sensitivity for all analytes. Detection and quantification were achieved using targeted analysis via positive ion scanning and multiple-reaction monitoring. The other mass spectrometer parameters are listed in Table 1.

\section{Optimization of chromatographic conditions}

Several gradients were investigated to optimize the peak resolution and sensitivity and to minimize the run time, which involved altering the flow rate, gradient, and concentration of acetonitrile. The MC congeners were detected on a triple-quadrupole mass spectrometer using multiple-reaction monitoring with transitions optimized manually to achieve maximum sensitivity.

\section{SPE column}

The separation efficiency of online-SPE columns depends on their retention of MCs. The fillers used in the onlineSPE column are usually silica gel as the matrix and a bonded phase with relatively weakly polar functional groups. The more polar components of the sample elute from the online-SPE column first, whereas the less polar components are retained on the column. Therefore, the online-SPE column with reverse-phase bonded, weakly polar silica gel adsorbent is optimal for the separation of MCs. Therefore, we evaluated the separation efficiency of XBridge C8 and Oasis HLB C18 by comparing the chromatographic resolution of eight different MCs $\left(20 \mathrm{ng} \mathrm{L}^{-1}\right)$. Compared with the commonly used Oasis HLB Direct Connect HP $(20 \mu \mathrm{m}, 2.1 \mu \mathrm{mm} \times 30 \mathrm{~mm})$, XBridge C8 is used for reversed-phase extraction, which is more suitable for nonpolar to medium-polarity target compounds. The online-SPE column used in this study was the XBridge C8 Direct Connect HP $(10 \mu \mathrm{m}$, $2.1 \mathrm{~mm} \times 30 \mathrm{~mm}$ ) to retain the strongly polar substances of eight different MCs eluted in the void volume of the Oasis HLB C18 column.

Water spiking with internal standard and filter membranes An appropriate internal standard can balance the change in the signal response intensity of the analyte caused by matrix interference under certain conditions and reduce the interference of the analyte loss during sample pretreatment $[27,28]$. Leucine enkephalin is used as the internal standard for the determination of MC. Xu et al. showed that MCs and leucine enkephalin can be separated well, and their recovery rates are similar owing to their similar structures [29].

Ultrapure water samples need to be filtered before analysis to protect the instruments and reduce matrix effects. However, MCs can be lost because hydrophilic filter membranes can partially absorb MCs through hydrogen bonds. Therefore, the recovery of three different membranes was evaluated in this study: polyethersulfone (PES), polytetrafluoroethylene (PTFE), and mixed cellulose ester (MCE). During the membrane evaluation experiment, the $\mathrm{MC}$ concentration was $50 \mathrm{ng} \mathrm{L}^{-1}$, and each membrane was evaluated four times in parallel.

Table 1 Compound-dependent MS/MS parameters of eight MC congeners

\begin{tabular}{lcllll}
\hline Compound & Precursor ion $(\boldsymbol{m} / \mathbf{z})$ & Qualitative ion $(\boldsymbol{m} / \mathbf{z})$ & Quantitative ion $(\boldsymbol{m} / \mathbf{z})$ & $\begin{array}{l}\text { Cone energy } \\
(\mathbf{V})\end{array}$ & Collision energy $(\mathrm{eV})$ \\
\hline MC-LR & & 135 & 213 & 85 & 75 \\
MC-YR & 995 & 135 & 213 & 85 & 85 \\
MC-RR & 1046 & 135 & 440 & 42 & 32 \\
MC-WR & 520 & 135 & 213 & 60 & 95 \\
MC-LA & 1069 & 135 & 776 & 40 & 80 \\
MC-LF & 911 & 135 & 213 & 42 & 68 \\
MC-LY & 986 & 135 & 985 & 45 & 80 \\
MC-LW & 1003 & 135 & 213 & 45 & 65 \\
\hline
\end{tabular}




\section{Mobile phases}

The two components of the mobile phase were termed as "A $+B$ " in this study. Six different mobile phases were evaluated: (1) methanol + water; (2) acetonitrile + water; (3) methanol with $0.1 \%(\mathrm{v} / \mathrm{v})$ formic acid + water with $0.1 \%(\mathrm{v} / \mathrm{v})$ formic acid; (4) acetonitrile with $0.1 \%(\mathrm{v} / \mathrm{v})$ formic acid + water with $0.1 \%(\mathrm{v} / \mathrm{v})$ formic acid; (5) acetonitrile with $0.25 \%(\mathrm{v} / \mathrm{v})$ formic acid + water with $0.1 \%$ $(\mathrm{v} / \mathrm{v})$ formic acid; (6) acetonitrile with $0.5 \%(\mathrm{v} / \mathrm{v})$ formic acid + water with $0.1 \%(\mathrm{v} / \mathrm{v})$ formic acid. The separation efficiency was evaluated by comparing the peak intensities of the eight different MCs with the column maintained at $35^{\circ} \mathrm{C}$.

Chromatographic resolution (R) was used to characterize the degree of separation of two adjacent chromatographic peaks, which is equal to the ratio of the difference between the retention times of adjacent chromatographic peaks $\left(t_{1}\right.$ and $\left.t_{2}\right)$ and the average peak width of the two chromatographic peaks $\left(w_{1}\right.$ and $\left.w_{2}\right)$, as shown in Eq. (1):

$$
R=\frac{t_{2}-t_{1}}{\frac{1}{2}\left(w_{1}+w_{2}\right)}=\frac{2\left(t_{2}-t_{1}\right)}{w_{1}+w_{2}},
$$

where $t_{1}$ and $t_{2}$ are the retention times of the first and second peaks, respectively, and $w_{1}$ and $w_{2}$ are the widths of the first and second peaks, respectively.

When $R<1$, the two peaks overlap; when $R=1$, the resolution can reach $98 \%$, and when $R=1.5$, the resolution can reach $99.7 \%$. When $R=1.5$, two adjacent components are usually considered to be completely separated.

\section{Gradient elution procedures}

Four gradient-elution procedures were employed: (1) the water phase was held at $100 \%$ for $4.1 \mathrm{~min}$, followed by a decrease to $0 \%$ over $2.9 \mathrm{~min}$, and then washed for $4 \mathrm{~min}$ at $100 \%$ before the next injection; (2) the water phase was held at $98 \%$ for $4.6 \mathrm{~min}$, followed by a decrease to $25 \%$ over $5.4 \mathrm{~min}$, and then washed for $2 \mathrm{~min}$ at $98 \%$ before the next injection; (3) the water phase was held at $95 \%$ for $4.1 \mathrm{~min}$, followed by a decrease to $60 \%$ over $1.9 \mathrm{~min}$ and another decrease to $5 \%$ over $3 \mathrm{~min}$, and then washed for $3 \mathrm{~min}$ at $95 \%$ before the next injection; and (4) the water phase was held at $95 \%$ for $6 \mathrm{~min}$, followed by a decrease to $5 \%$ over $3 \mathrm{~min}$, and then washed for $2 \mathrm{~min}$ at $95 \%$ before the next injection.

\section{Method validation}

Seven concentration sequences $(10,20,50,100,200$, 500 , and $1000 \mathrm{ng} \mathrm{L}^{-1}$ ) of the standard MC solution were detected according to the finalized method. Leucine enkephalin (10 ng $\mathrm{L}^{-1}$ ) was added as the internal standard, and the authenticity and absolute recovery of the analyte were calculated. A linear regression and standard curve were applied with the injection concentration $(x)$ corresponding to the peak area $(y)$.

Three mixed standard solutions with high (500 ng L $\left.{ }^{-1}\right)$, medium $\left(100 \mathrm{ng} \mathrm{L}^{-1}\right)$ and low $\left(20 \mathrm{ng} \mathrm{L}^{-1}\right)$ concentrations were added to the blank water samples. After filtration by using a $0.22-\mu \mathrm{m}$ MCE membrane, the concentrations of the target substances in the water samples were determined by online-SPE UPLC-MS/MS. Six samples of each concentration were taken for parallel experiments, and the recovery rate and relative standard deviation (RSD) were calculated. The LOD $\left(\mathrm{ng} \mathrm{L^{-1 }}\right)$ and LOQ $\left(\mathrm{ng} \mathrm{L}^{-1}\right)$ were calculated using signal-to-noise ratios (SNRs) of 3 and 10 based on the lower-end calibration curve levels. The accuracy values were calculated as the average value of the recovery for concentrations of 20, 100, and $500 \mathrm{ng}$ $\mathrm{L}^{-1}$, and the precision values were calculated as the average RSD for concentrations of 20, 100, and $500 \mathrm{ng} \mathrm{L}^{-1}$.

\section{Water samples for method development}

Twelve water samples $(\mathrm{CH} 1, \mathrm{CH} 2, \ldots \mathrm{CH} 12)$ collected from Chaohu Lake (Anhui Province, China) in August 2020 were used to validate the method. At least 12 zones in Chaohu Lake were chosen for water sample collection, and $500 \mathrm{~mL}$ of water was collected from depths of $0-50 \mathrm{~cm}$ in each zone after the surface scum was removed. Then, $100 \mathrm{~mL}$ of each water sample was filtered in situ using a $0.45-\mu \mathrm{m}$ cellulose acetate filter membrane (JiuDing, China) in a $120-\mathrm{mL}$ polypropylene bottle. The samples were then placed in a cooler with ice packs and transferred to the laboratory for further treatment. The 12 sampling points are shown in Fig. 1.

Each water sample of $20 \mathrm{~mL}$ was filtered using a disposable medical syringe coupled with a $0.22-\mu \mathrm{m}$ filter in the injection vials; each sample was spiked with $10 \mathrm{ng} \mathrm{L}^{-1}$ of internal standard prior to injection. To quantify the MCs, a seven-point mixed standard calibration curve in the range of $10-1000 \mathrm{ng} \mathrm{L}^{-1}$ was created based on an initial sample size of $20 \mathrm{~mL}$.

\section{Results and discussion}

\section{Online-SPE column selection}

Chromatograms of the mixed standard solutions obtained using the Oasis HLB C18 column and XBridge C8 column are shown in Fig. 2.

A comparison of the separation effect of the two chromatographic columns revealed that MC-LA, LY, LW, and LF (4/8) were unsuccessfully eluted from the Oasis HLB C18 column because these four substances are more polar than the others, which makes their elution from the column more difficult, as they are more strongly adsorbed; thus, the chromatographic peak is not completely separated. However, The XBridge C8 column separated all congeners well. The resolutions of the 


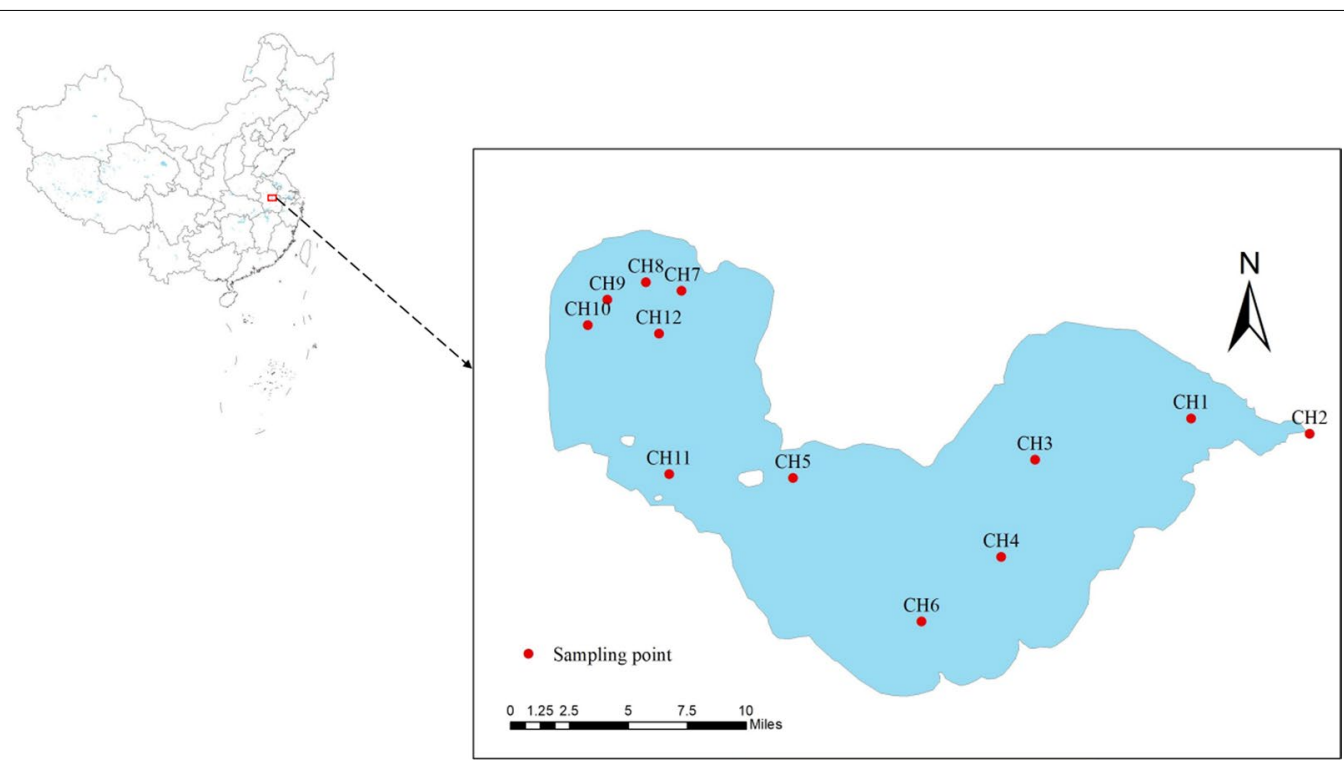

Fig. 1 Sampling distribution in Chaohu Lake
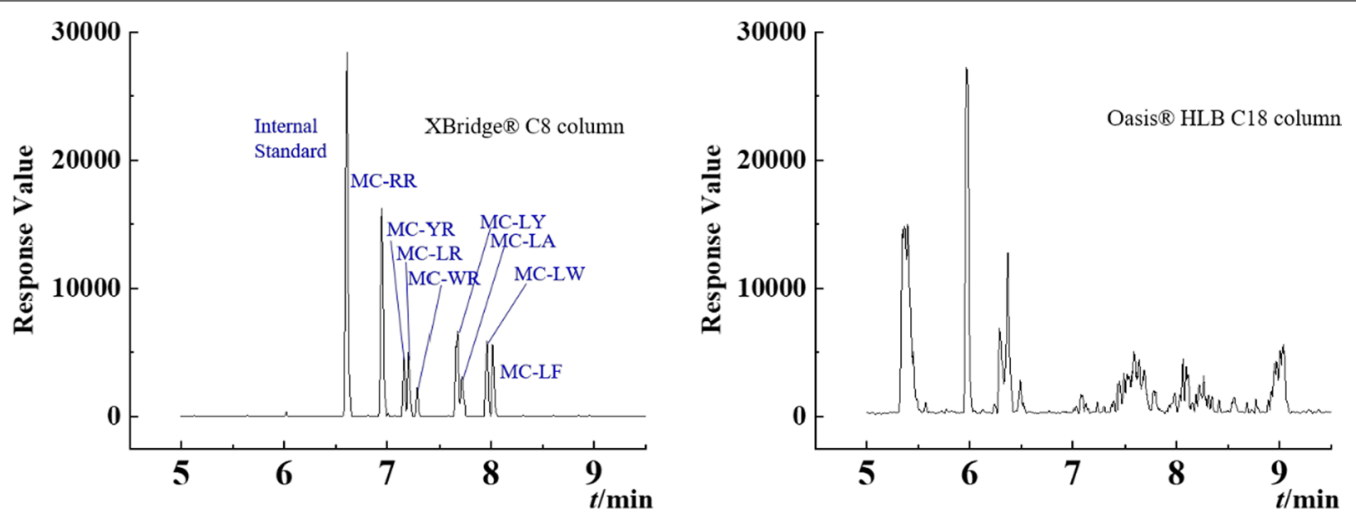

Fig. 2 Chromatograms of mixed standard solution using two different columns

chromatographic peaks were as follows: $2.47,0.73,1.13$, $5.43,1.11,4.36$, and 0.83 . The two peaks of MC-YR \& MC-LR and MC-LF \& MC-LW overlapped slightly. The resolution between the peaks of the other adjacent substances was $>1$, indicating good separation. The Oasis HLB C18 column cannot effectively elute and separate the four MCs with similar polarities. Owing to the differences in the internal structure of the column packing, the $\mathrm{C} 18$ column had better retention characteristics than the $\mathrm{C} 8$ column. Therefore, the $\mathrm{C} 8$ column is more suitable for the analysis of macromolecular substances and often used to analyze and separate substances with lower molecular weights. Although the Oasis HLB C18 column did not separate the four MCs efficiently in this study, the separation time $(8.4 \mathrm{~min})$ was $4 \mathrm{~min}$ shorter than those

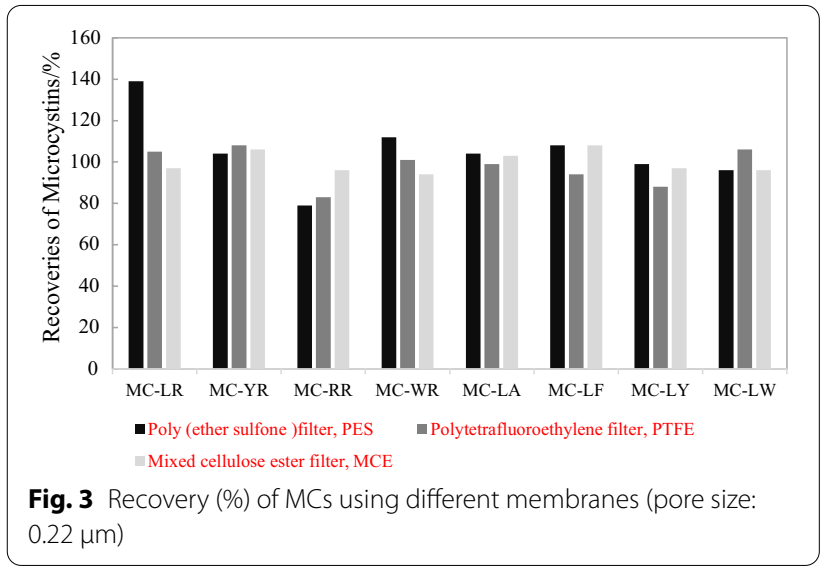



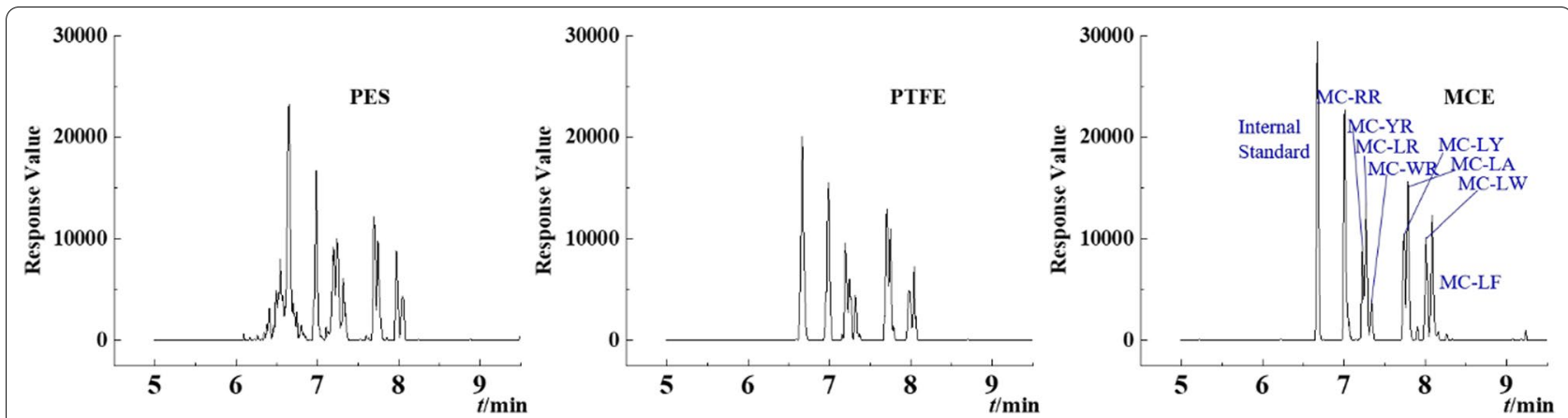

Fig. 4 Chromatograms obtained using three different filter membranes (pore size: $0.22 \mu \mathrm{m}$ )

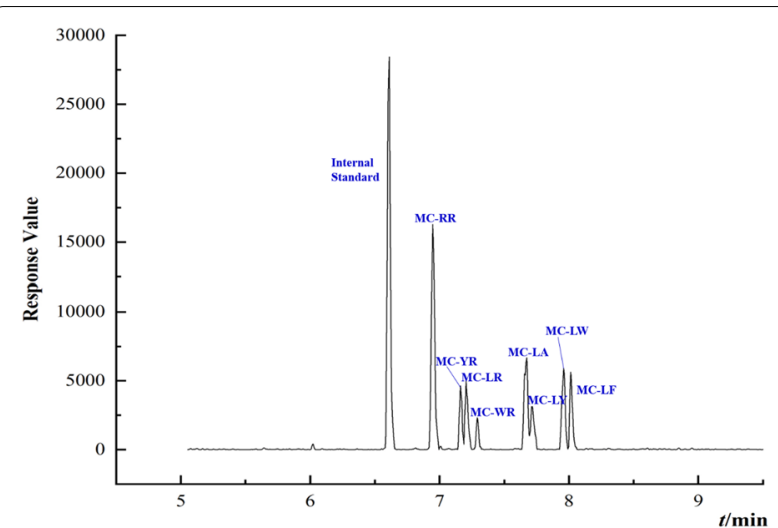

Fig. 5 Chromatogram featuring the eight mixed standard MC solutions (20 $\left.\mathrm{ng} \mathrm{L}^{-1}\right)$ with mobile phases of (4): acetonitrile with $0.1 \%$ $(\mathrm{v} / \mathrm{v})$ formic acid + water with $0.1 \%(\mathrm{v} / \mathrm{v})$ formic acid

achieved using previously developed methods $[10,30$, 31].

\section{Selection of membranes}

The filter membranes removed eight different MCs efficiently from water with recovery rates of $79-108 \%$ (Fig. 3). For reference, the US EPA criterion is $70-130 \%$ $[22,32]$. The chromatograms obtained under different filter membrane conditions are shown in Fig. 4. The MCE filter retained the lowest amount of MCs compared to the PES and PTFE filters because the MCs recovery rates were greater than $90 \%$. A similar pattern of recovery also indicated that the MCs were stable on the MCE. Thus, the MCE filter membrane was selected as the optimal membrane for this study. Note that the recovery of $M C-R R$ is lower than that of the other congeners because MC-RR contains two arginine molecules, unlike the other congeners. This increases the formation of cation bridges with the protonated arginine molecule, which is a well-known mechanism for binding onto the surface of the organic phase [33]. Moreover, protonated arginine can form additional hydrogen bonds with the surface of the MCE membrane. Consequently, MCE retains MC-RR during filtration, which also explains the lower recovery rate of MC-RR in this study.

\section{Determination of mobile phase}

In this study, acetonitrile and ultrapure water were selected as the mobile phases of the online-SPE system, and acetonitrile with formic acid, along with water with formic acid were selected as the mobile phases of the UPLC system. The chromatograms of the mobile phase obtained under the six different conditions are shown in Fig. 5.

The chromatographic peak separation of the eight different MCs was observed under six different conditions. Acetonitrile, as the organic phase can simultaneously separate eight substances better than methanol with a higher response value. A comparison of the chromatograms obtained with different concentrations of formic acid in acetonitrile showed that the effect was the strongest at $0.1 \%$ formic acid. The Oasis HLB C18 column cannot effectively elute and separate the four MCs with similar polarities because the addition of formic acid in the mobile phase facilitates the protonation of positive ions and maintains the ionization state of the sample in the mobile phase. Therefore, we chose $0.1 \%$ formic acid+acetonitrile as the organic phase in the mobile phase.

\section{Determination of gradient-elution procedures}

The gradient-elution procedure of the mobile phase affects the retention time, peak shape, and peak resolution of the chromatogram. Procedure (1) which was previously described, was determined to be the most suitable, resulting in the best chromatographic resolution and material peak intensity. Therefore, this procedure was selected for the experiments. The chromatogram of the eight different MCs under this condition is shown in Fig. 6. 


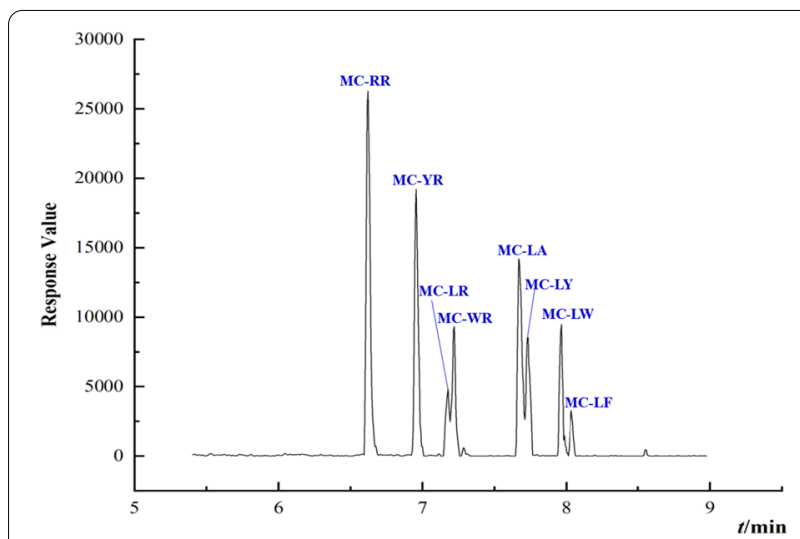

Fig. 6 Chromatogram obtained under gradient-elution procedure (1)

\section{Recovery of MCs from ultrapure water}

For the eight different MCs, the absolute recovery rates ranged from 40.9 to $135 \%$. The recoveries of MC-RR and MC-WR were relatively low, with recovery rates ranging from 58.9 to $74.1 \%$ and $40.9 \%$ to $78.4 \%$, respectively. These lower recovery rates may have been caused by the adsorption of the MCE membrane. By contrast, the recovery rates of MC-LA and MC-LF at medium, and high concentrations were relatively high; this may be due to the influence of the matrix during testing. Except for MC-RR and MC-WR, the recovery rates of all other MCs meet the standard. As shown in Table 2, the RSDs of the measured values of the low-, medium-, and high-concentration standard samples are in the range of $0.88-9.83 \%$, $6.43-9.72 \%$, and $2.10-9.83 \%$, respectively, meeting the daily measurement requirements.

\section{Analytical method validation}

The seven-point calibration curves ranging from 10 to $1000 \mathrm{ng} \mathrm{L}^{-1}$ was fitted by using linear regression with large coefficients of determination $\left(R^{2}=0.990-0.995\right)$ over a linear range spanning 2-3 orders of magnitude (Table 3). The LODs for the optimized chromatographic conditions were $0.02-0.37 \mathrm{ng} \mathrm{\textrm {L } ^ { - 1 }}$, whereas the LOQs ranged from 0.07 to $1.24 \mathrm{ng} \mathrm{L}^{-1}$. The accuracy of the MC standard solution was $86.4 \%$, which falls within the acceptable range of accuracy based on the US EPA Method 544. The precision of the samples was 7.26\%.

Table 2 Experimental recovery parameters $(n=6)$

\begin{tabular}{|c|c|c|c|c|c|c|}
\hline \multirow[t]{2}{*}{ Compound } & \multicolumn{2}{|l|}{$20 \mathrm{ng} \mathrm{L}^{-1}$} & \multicolumn{2}{|c|}{$100 \mathrm{ng} \mathrm{L}^{-1}$} & \multicolumn{2}{|c|}{$500 \mathrm{ng} \mathrm{L}^{-1}$} \\
\hline & RSD (\%) & Recovery (\%) & RSD (\%) & Recovery (\%) & RSD (\%) & Recovery (\%) \\
\hline MC-LR & 6.26 & 96.2 & 8.49 & 94.2 & 7.08 & 80.3 \\
\hline$M C-Y R$ & 0.88 & 81.7 & 6.43 & 92.2 & 4.87 & 85.8 \\
\hline MC-RR & 5.61 & 74.1 & 7.38 & 64.8 & 2.10 & 58.9 \\
\hline MC-WR & 8.86 & 78.4 & 6.49 & 45.1 & 8.22 & 40.9 \\
\hline MC-LA & 9.83 & 79.5 & 7.26 & 85.7 & 9.39 & 135.9 \\
\hline MC-LF & 8.21 & 67.6 & 9.67 & 134.9 & 9.83 & 106.5 \\
\hline MC-LY & 7.49 & 87.8 & 6.46 & 93.1 & 9.38 & 78.2 \\
\hline MC-LW & 7.04 & 71.4 & 9.72 & 103.6 & 7.21 & 104.4 \\
\hline
\end{tabular}

Table 3 Method parameters for MCs under the optimized chromatographic conditions and quantified by online-SPE UHPLC-MS/MS

\begin{tabular}{|c|c|c|c|c|c|c|c|c|}
\hline Compound & $\begin{array}{l}\text { Retention } \\
\text { time (min) }\end{array}$ & $\begin{array}{l}\text { Linear range } \\
\left(\mathrm{ng} \mathrm{L}^{-1}\right)\end{array}$ & $\mathrm{R}^{2}$ & SNR & LOQ $\left(\mathrm{ng} \mathrm{L}^{-1}\right)$ & $\operatorname{LOD}\left(\mathrm{ng} \mathrm{L}^{-1}\right)$ & Accuracy (\%) & Precision (\%) \\
\hline$M C-L R$ & 7.20 & $10-1000$ & 0.991 & 423 & 0.24 & 0.07 & 90.2 & 7.28 \\
\hline$M C-Y R$ & 7.16 & 10-1000 & 0.993 & 510 & 0.20 & 0.06 & 86.6 & 4.06 \\
\hline MC-RR & 6.95 & $5-500$ & 0.995 & 753 & 0.07 & 0.02 & 65.9 & 5.03 \\
\hline MC-WR & 7.29 & $50-1000$ & 0.992 & 405 & 1.24 & 0.37 & 54.8 & 7.86 \\
\hline MC-LA & 7.67 & $10-1000$ & 0.991 & 458 & 0.22 & 0.07 & 100 & 8.83 \\
\hline MC-LF & 8.01 & $10-1000$ & 0.995 & 365 & 0.27 & 0.08 & 103 & 9.24 \\
\hline MC-LY & 7.72 & $10-1000$ & 0.990 & 202 & 0.50 & 0.15 & 86.4 & 7.78 \\
\hline MC-LW & 7.96 & $10-1000$ & 0.994 & 530 & 0.19 & 0.06 & 120 & 7.99 \\
\hline
\end{tabular}


Table 4 Concentrations (ng $\mathrm{L}^{-1}$ ) of MCs in water from Chaohu Lake, China

\begin{tabular}{llll}
\hline Compound & $\begin{array}{l}\text { Mean value } \\
\left(\mathbf{n g ~ L} \mathbf{~}^{-1}\right)\end{array}$ & $\begin{array}{l}\text { Concentration } \\
\text { range }\left(\mathbf{n g ~ L}^{-1}\right)\end{array}$ & $\begin{array}{l}\text { Detected } \\
\text { frequency } \\
\text { (\%) }\end{array}$ \\
\hline MC-LR & 83 & $19-119$ & 100 \\
MC-YR & 21 & $15-40$ & 100 \\
MC-RR & 55 & $37-169$ & 100 \\
MC-WR & 24 & $23-29$ & 91.7 \\
MC-LA & 6 & $5.8-6.4$ & 91.7 \\
MC-LF & 7 & $7-8$ & 83.3 \\
MC-LY & 10 & $8-21$ & 75 \\
MC-LW & 9 & $8.5-8.7$ & 75 \\
\hline
\end{tabular}

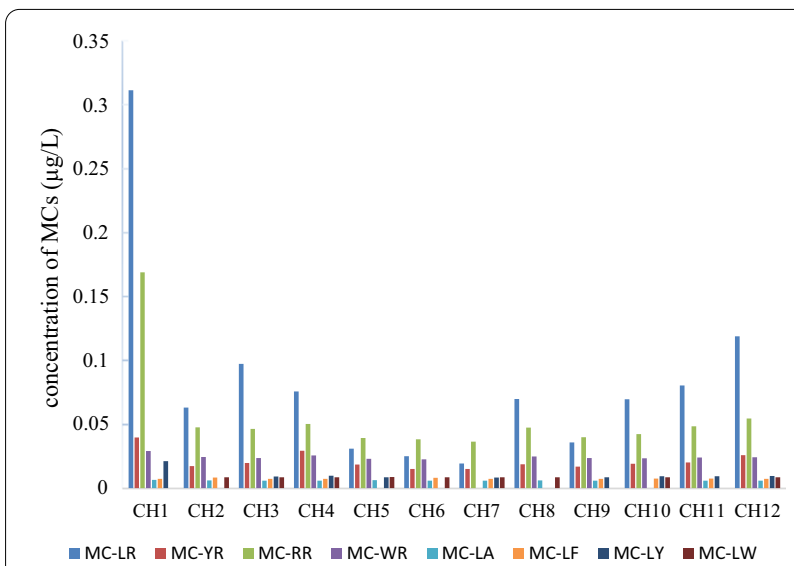

Fig. 7 Concentrations of MCs at 12 sampling points in Chaohu Lake, China

\section{Application of the optimized method to quantify MCs in lake water}

The optimized method was used to analyze MCs in 12 water samples collected from Chaohu Lake, China; eight different MCs were detected. Among the 12 lake water samples, the detected frequency (DF) of MC-LR, MC-YR, and MC-RR were the highest, with a value of 100\%; MC-WR and MC-LA were detected both in 11 samples (with a DF value of 91.7\%). MC-LF exhibited the third-highest DF of 83.3\%; and the DF values of MC-LY and MC-LW were both $75 \%$. The mean concentrations of the total MCs ranged from 101 to $590 \mathrm{ng} \mathrm{L}^{-1}$, whereas the total concentration level was below the WHO limit of $1000 \mathrm{ng} \mathrm{L}^{-1}$ for MC-LR (Table 4 and Fig. 7). For the single index, the top three substances with the highest mean concentrations were MC-LR (83 ng L ${ }^{-1}$ ), MC-RR (55 ng $\left.\mathrm{L}^{-1}\right)$, and $\mathrm{MC}-\mathrm{WR}\left(24 \mathrm{ng} \mathrm{L}^{-1}\right)$, respectively.

\section{Conclusions}

Automated sample preparation can considerably reduce the material and labor required to produce a sample for analysis. Online-SPE and high SNR significantly reduced the amount of labor and sample size required for the analysis compared to offline sample enrichment protocols. For all analytes, excellent linearity was observed for samples with concentrations of 10-1000 $\mathrm{ng} \mathrm{L^{-1 }}$ $\left(r^{2} \geq 0.99\right)$. The RSD values were all lower than $10 \%$.

The method of determination after optimizing the chromatographic conditions of online-SPE UPLC-MS/ MS was robust and reliable for eight different MCs. This method showed high sensitivity and high resolution for the separation of eight MC congeners with LODs ranging from 0.020 to $0.371 \mathrm{ng} \mathrm{L}^{-1}$ and LOQs ranging from 0.066 to $1.235 \mathrm{ng} \mathrm{L}^{-1}$, which meet the requirements of the WHO control standards for MCs. This UPLC-MS/ MS method is fast and sensitive because of the simple preprocessing steps and effectively reduces interference in the surrounding environment.

The developed method has the characteristics of high pretreatment efficiency, strong selectivity; and high sensitivity; meets the requirements for the detection of eight different MCs in surface water; provides a reference for early-warning forecasts of MCs; and is a key to ensuring the safety of drinking water sources.

\section{Abbreviations \\ Online-SPE UPLC-MS/MS: Online solid-phase extraction-ultra performance liquid chromatography coupled with tandem mass spectrometry; MCs: Microcystins; WHO: World Health Organization; IARC: International Agency for Research on Cancer; ELISA: Enzyme-linked immunosorbent assay; LC-MS/ MS: Liquid chromatography with tandem mass spectrometry; UPLC-MS/ MS: Ultra-performance liquid chromatography coupled with tandem mass spectrometry; SPE: Solid-phase extraction; PES: Polyethersulfone; PTFE: Polyte- trafluoroethylene; MCE: Mixed cellulose ester filters; ESI+: Electrospray positive mode; RSD: Relative standard deviation; LOD: Limit of detection; LOQ: Limit of quantification; SNR: Signal-to-noise ratios.}

\section{Acknowledgements}

None applicable.

\section{Authors' contributions}

Conceptualization, XQ, SG, YL, XL; methodology, SG, CL,XZ; formal analysis, XQ, $S G, Y L, X L$ and $X Z$; investigation, $X Q, S G, L J, R Z, T Q, Y L$; resources, $Y L, X Z$; data curation, SG, RZ, TQ,YL; writing —original draft preparation, $X Q$, SG; writingreview and editing, $Y L, X Q$, and $X Z$; visualization, $S G$; supervision, $Y L$; project administration, YL; funding acquisition, YL. All authors read and approved the final manuscript.

\section{Funding}

This work was supported by the Special Research Funding for the Public Benefits sponsored by the Major Science and Technology Program for Water Pollution Control and Treatment (No. 2017ZX07401004).

Availability of data and materials

All data generated or analyzed during this study are included in this published article. 


\section{Declarations}

Ethics approval and consent to participate

Not applicable.

\section{Consent for publication}

Not applicable.

\section{Competing interests}

The authors declare that they have no competing interests.

\section{Author details}

${ }^{1}$ Environmental Standards Institute of Ministry of Ecology and Environment of the People's Republic of China, Chinese Research Academy of Environmental Sciences, Beijing 100012, China. ${ }^{2}$ State Key Laboratory of Environmental Criteria and Risk Assessment, Chinese Research Academy of Environmental Sciences, Beijing 10012, China. ${ }^{3}$ Institute of Analysis and Testing, Beijing Academy of Science and Technology (Beijing Center for Physical and Chemical Analysis), Beijing 100089, China.

Received: 20 June 2021 Accepted: 19 September 2021

Published online: 12 November 2021

\section{References}

1. Van Apeldoorn ME, Van Egmond HP, Speijers GJA, Bakker GJ (2007) Toxins of cyanobacteria. Mol Nutr Food Res 51:7-60. https://doi.org/10.1002/ mnfr.200600185

2. Bouaïcha N, Miles CO, Beach DG, Labidi Z, Djabri A, Benayache NY, Nguyen-Quang T (2019) Structural diversity, characterization and toxicology of microcystins. Toxins 11:714. https://doi.org/10.3390/toxins1112 0714

3. World Health Organization (WHO). Cynobacterial Toxins: Microcystin-LR WHO Guidelines for Drinking Water Quality. Geneva: WHO. 2011. p. 344.

4. Graham JL, Loftin KA, Meyer MT, Ziegler AC (2010) Cyanotoxin mixtures and taste-and-odor compounds in cyanobacterial blooms from the Midwestern United States. Environ Sci Technol 44:7361-7368. https://doi. org/10.1021/es1008938

5. Kruger T, Wiegand C, Kun L, Luckas B, Pflugmacher S (2010) More and more toxins around-analysis of cyanobacterial strains isolated from Lake Chao (Anhui Province, China). Toxicon 56:1520-1524. https://doi.org/10. 1016/j.toxicon.2010.09.004

6. Lu KY, Chiu YT, Burch M, Senoro D, Lin TF (2019) A molecular-based method to estimate the risk associated with cyanotoxins and odor compounds in drinking water sources. Water Res. https://doi.org/10.1016/j. watres.2019.114938

7. Shang L, Feng M, Xu X, Liu F, Ke F, Li W (2018) Co-occurrence of microcystins and taste-and-odor compounds in drinking water source and their removal in a full-scale drinking water treatment plant. Toxins (Basel) 10:1-17. https://doi.org/10.3390/toxins10010026

8. Yen HK, Lin TF, Liao PC (2011) Simultaneous detection of nine cyanotoxins in drinking water using dual solid-phase extraction and liquid chromatography-mass spectrometry. Toxicon 58:209-218. https://doi. org/10.1016/j.toxicon.2011.06.003

9. Zhang L, Liu JT, Zhang DW, Luo LG, Liao QG, Yuan L, Wu NC (2018) Seasonal and spatial variations of microcystins in Poyang Lake, the largest fresh water lake in China. Environ Sci Pollut Res 25:6300-6307. https://doi. org/10.1007/s11356-017-0967-1

10. Lu WG, Lin WY (2001) Investigation on primary liver cancer mortality trends and the high-risk factors in 1969-1999 in Haimen. J Transport Med 15:469-470

11. Zhou XF, Dong ZH, Yu SZ (1999) A study of influencing factors on high incidence of liver cancer in Taixing. China Cancer 8(3):350-351

12. Catherine A, Bernard C, Spoof L, Bruno M (2017) Microcystins and Nodularins. In: Meriluoto J, Spoof L, Cood GA (eds) Handbook of cyanobacterial monitoring and cyanotoxin analysis. Wiley, pp 107-126

13. Díez-Quijada L, Prieto Al, Guzmán-Guillén R, Jos A, Cameán AM (2018) Occurrence and toxicity of microcystin congeners other than MC-LR and
MC-RR: A review. Food Chem Toxicol 125:106-132. https://doi.org/10. 1016/j.fct.2018.12.042

14. Buratti FM, Anganelli M, Vichi S, Stefanelli M, Scardala S, Testai M, Funari E (2017) Cyanotoxins: Producing organisms, occurrence, toxicity, mechanism of action and human health toxicological risk evaluation. Arch Toxicol 91:1049-1130. https://doi.org/10.1007/s00204-016-1913-6

15. Testai E, Buratti FM, Funari E, Manganelli M, Vichi S, Arnich N, Biré R, Fessard V, Sialehaamoa A (2016) Review and analysis of occurrence, exposure and toxicity of cyanobacteria toxins in food. EFSA Support. 998:309. https://doi.org/10.2903/sp.efsa.2016.EN-998

16. Kleinteich J, Puddick J, Wood S, Hildebrand F, Laughinghouse H, Pearce $D_{\text {, }}$ Wilmotte A (2018) Toxic Cyanobacteria in Svalbard: Chemical Diversity of Microcystins Detected Using a Liquid Chromatography Mass Spectrometry Precursor Ion Screening Method. Toxins 10(4):147. https://doi.org/10. 3390/toxins 10040147

17. McElhiney J, Lawton LA (2005) Detection of the cyanobacterial hepatotoxins microcystins. Toxicol Appl Pharmacol 203:219-230. https://doi.org/ 10.1016/j.taap.2004.06.002

18. Merel S, Walker D, Chicana R, Snyder S, Baures E, Thomas O (2013) State of knowledge and concerns on cyanobacterial blooms and cyanotoxins. Environ Int 59:303-327. https://doi.org/10.1016/j.envint.2013.06.013

19. Oehrle SA, Southwell B, Westrick J (2010) Detection of various fresh water cyanobacterial toxins using ultra-performance liquid chromatography tandem mass spectrometry. Toxicon 55:965-972. https://doi.org/10. 1016/j.toxicon.2009.10.001

20. He X, Stanford BD, Adams C, Rosenfeldt EJ, Wert EC (2017) Varied influence of microcystin structural difference on ELISA cross-reactivity and chlorination efficiency of congener mixtures. Water Res 126:515-523. https://doi.org/10.1016/j.watres.2017.09.037

21. Sangolkar LN, Maske SS, Chakrabarti T (2006) Methods for determining microcystins (peptide hepatotoxins) and microcystin-producing cyanobacteria. Water Res 40:3485-3496. https://doi.org/10.1016/j.watres.2006. 08.010

22. United States Environmental Protection Agency (U.S. E.P.A), 2015. METHOD 544. Determination of microcystins and nodularin in drinking water by solid phase extraction and liquid chromatography/tandem mass spectrometry (LC/MS/MS). U.S. E.P.A, Washington DC. https://cfpub. epa.gov/si/si_public_file_download.cfm?p_download_id $=522920 \&$ Lab=NERL. Accessed 21 May 2015.

23. Meriluoto JAO, Spoof LEM. Cyanotoxins: sampling, sample processing and toxin uptake. In: Hudnell HK Eds. Cyanobacterial Harmful Algal Blooms: State of the Science and Research Needs; 2008, pp. 483.

24. Ortea PM, Allis O, Healy BM, Lehane M, Shuilleabhain A, Furey A, James KJ (2004) Determination of toxic cyclicheptapeptides by liquid chromatography with detection using ultra-violet, protein phosphatase assay and tandem mass spectrometry. Chemosphere 55:1395-1402. https://doi. org/10.1016/j.chemosphere.2003.11.025

25. Spoof L, Meriluoto J (2002) Rapid separation of microcystins and nodularin using a monolithic silica C-18 column. J Chromatogr A 947:237-245. https://doi.org/10.1016/S0021-9673(01)01605-3

26. Welker M, Bickel H, Fastner J (2002) HPLC-PDA detection of cylindrospermopsin - opportunities and limits. Water Res 36:4659-4663. https://doi. org/10.1016/S0043-1354(02)00194-X

27. Tan A, Lévesque IA, Lévesque IM (2011) Analyte and internal standard cross signal contributions and their impact on quantitation in LC-MS based bioanalysis. J Chromatogr B 879:1954-1960. https://doi.org/10. 1016/j.jchromb.2011.05.027

28. Zenkevich IG, Makarov ED (2007) Chromatographic quantitation at losses of analyte during sample preparation: Application of the modified method of double internal standard. J Chromatogr A 1150:117-123. https://doi.org/10.1016/j.chroma.2006.08.083

29. Xu W, Chen Q, Zhang T (2008) Development and application of ultra-performance liquid chromatography-electrospray ionization tandem triple quadrupole mass spectrometry for determination of seven microcystins in water samples. Anal Chim Acta 626:28-36. https://doi.org/10.1002/ cjoc.201090074

30. Beltran E, Ibanez M, VicenteSancho J, Hernandez F (2012) Determination of six microcystins and nodularin in surface and drinking waters by on-line solid phase extraction-ultra high pressure liquid chromatography 
tandem mass spectrometry. J Chromatogr A 1266:61-68. https://doi.org/ 10.1016/j.chroma.2012.10.017

31. Triantis T, Tsimeli K, Kaloudis T, Thanassoulias N, Lytras E, Hiskia A (2010) Development of an integrated laboratory system for the monitoring of cyanotoxins in surface and drinking waters. Toxicon 55:979-989. https:// doi.org/10.1016/j.toxicon.2009.07.012

32. Zhang Y, Whalen JK, Duy SV, Munoz G, Husk BR, Sauvé S (2020) Improved extraction of multiclass cyanotoxins from soil and sensitive quantification with on-line purification liquid chromatography tandem mass spectrometry. Talanta 216:120923. https://doi.org/10.1016/j.talanta.2020.120923
33. Park JA, Yang B, Jang M, Kim JH, Kim SB, Park HD, Park HM, Lee SH, Choi JW (2019) Oxidation and molecular properties of microcystin-LR, microcystin-RR and anatoxin-a using UV-light-emitting diodes at $255 \mathrm{~nm}$ in combination with H2O2. Chem Eng J. https://doi.org/10.1016/j.cej. 2019.02.101

\section{Publisher's Note}

Springer Nature remains neutral with regard to jurisdictional claims in published maps and institutional affiliations.

\section{Submit your manuscript to a SpringerOpen ${ }^{\circ}$ journal and benefit from:}

- Convenient online submission

- Rigorous peer review

- Open access: articles freely available online

- High visibility within the field

- Retaining the copyright to your article

Submit your next manuscript at $\boldsymbol{\nabla}$ springeropen.com 